\title{
Signifikansi Kepemilikan Tanah Kanaan Bagi Bangsa Israel Di Perjanjian Lama
}

\author{
Irfan Feriando Simanjuntak, ${ }^{1}{ }^{\text {Purba Deo, }},{ }^{2}$ Otieli Harefa ${ }^{3}$ \\ Prodi Teologi, STT Real Batam \\ Prodi Teologi, STT Real Batam \\ Prodi Teologi, STT Real Batam \\ irfansimanjuntak81@gmail.com
}

\begin{abstract}
Canaanite land ownership for the Israelites is a strong theme taught in the Old Testament. This ownership was repeatedly expressed as being given by God to them through promises that were revealed to Abraham and passed on to his descendants. From the time of Moses and especially Joshua, even to the time that the ownership of the land became an important issue in the life of the nation, both physically and spiritually. Their ownership is very significant for them because it reaches broadly the full relevance of their lives as God's people. Through qualitative methods that are descriptive, in this article, the significance relates to matters that are theological in nature, namely relating to the fulfillment of the covenant, the place of rest of the Israelites and God and the maintenance of the faith and identity of the Israelites. Thus, for the Israelites in the Old Testament, it was very important to own the land of Canaan, that Testament land.
\end{abstract}

Keywords: Canaan, land, covenants, Israel

\begin{abstract}
Abstrak
Kepemilikan tanah Kanaan bagi orang Israel merupakan tema yang kuat diajarkan di Perjanjian Lama. Kepemilikan ini berkali-kali diungkapkan sebagai diberikan Allah kepada mereka melalui janji yang dinyatakan kepada Abraham dan diteruskan kepada keturunannya. Sejak jaman Musa dan khususnya Yosua, bahkan sampai masa-masa seterusnya kepemilikan tanah tersebut menjadi isu yang penting dalam kehidupan bangsa Israel baik secara jasmani maupun rohani. Kepemilikannya sangat signifikan bagi mereka karena menjangkau luas seluruh relevansi kehidupan mereka sebagai umat Allah. Melalui metode kualitatif yang bersifat deskriptif, dalam artikel ini, signifikansi tersebut berkaitan dengan hal-hal yang bersifat teologis, yaitu berkaitan dengan penggenapan perjanjian, tempat perhentian bangsa Israel dan Tuhan dan penjagaan iman dan identitas bangsa Israel. Dengan demikian, bagi orang Israel di Perjanjian Lama, adalah sangat penting untuk memiliki tanah Kanaan, tanah Perjanjian tersebut.
\end{abstract}

Kata Kunci: Kanaan, tanah, perjanjian, Israel

\section{PENDAHULUAN}

Allah bertindak di medan sejarah. Ia turun tangan menyatakan kuasa kasih-Nya di muka bumi, tempat kediaman manusia. Di bumi ini, bukannya di awan-awan, Ia mengerjakan kehendak dan rencana-Nya termasuk di dalamnya memberikan diri-Nya untuk ditemui oleh manusia, agar umat-Nya bisa bersekutu dengan-Nya dan menikmati kepenuhan hidup di dalam hadirat-Nya. Pemberian tanah Kanaan kepada Israel pernah berlangsung di medan sejarah dunia. Umat Israel selalu menganggap Kanaan sebagai 
tempat kediaman dan sebagai miliknya yang sah, juga sekaligus tempat kediaman Tuhan. Dimulai dari janji Allah kepada Abraham, kepemilikan terhadap tanah Kanaan menjadi sesuatu yang esensial dalam hidup bangsa Israel selanjutnya. Itulah sebabnya pada zaman Musa dan khususnya Yosua, berbagai upaya mereka lakukan untuk memiliki tanah tersebut sesuai dengan janji Tuhan, walau mereka juga sadar bahwa sesungguhnya mereka hanyalah pendatang, penduduk dan pemilik yang "baru”. Kanaan bukanlah milik mereka sejak awal, karena tema bahwa tanah itu diberikan kepada mereka selalu diulang-ulang. ${ }^{1}$ Ini merupakan kesadaran orang Israel, sehingga memang dapat dikatakan Kanaan adalah tanah yang awalnya bukan milik Israel namun akhirnya diberikan kepada mereka oleh Allah untuk menjadi milik pusaka mereka sampai selama-lamanya.

Apa tujuan Allah memberikan tanah Kanaan bagi Israel? Atau dengan kata lain, apa signifikansi kepemilikan tanah Kanaan bagi bangsa Israel? Hal inilah yang dibahas di dalam makalah ini. Makalah ini bertujuan untuk menguraikan signifikansi atau kepentingan kepemilikian tanah Kanaan bagi bangsa Israel di Perjanjian Lama. Hal ini dirasa perlu untuk diteliti sehingga alasan-alasan teologis terhadap hal tersebut bisa diangkat ke permukaan agar orang percaya pada masa kini, khususnya para pembelajar Perjanjian Lama bisa belajar daripadanya. Dengan demikian, makalah ini ditulis dengan metode kualitatif deskriptif melalui studi terhadap literatur-literatur terkait.

\section{METODE}

Dalam penelitian ini, penulis menggunakan metode penelitian Deskriptif kualitatif. Proses penelitian dimulai dengan menyusun asumsi dasar dan aturan berpikir yang akan digunakan dalam penelitian. Asumsi dan aturan berpikir tersebut selanjutnya diterapkan secara teratur dalam pengumpulan dan pengolahan data untuk memberikan penjelasan dan argumentasi berupa pengumpulan dan penyusunan data, serta analisis dan penafsiran data tersebut untuk menjelaskan fenomena dengan aturan berpikir ilmiah yang diterapkan secara sistematis tanpa menggunakan model kuantitatif. Dalam penjelasannya lebih menekankan pada kekuatan analisis data pada sumber-sumber data yang ada. "Sumber-sumber tersebut di peroleh dari berbagai buku dan tulisan-tulisan lainnya dengan mengandalkan teori-teori yang ada untuk diitafsirkan secara jelas dan mendalam untuk menghasilkan skripsi dan antiskripsi.",

Untuk menguji keabsahan data yang didapat sehingga benar-benar sesuai dengan tujuan dan maksud penelitian, maka peneliti menggunakan teknik triangulasi. Triangulasi data adalah teknik pemeriksaan data yang memanfaatkan sesuatu yang lain diluar data tersebut untuk keperluan pengecekan atau sebagai pembanding data tersebut. ${ }^{3}$ Adapun triangulasi yang digunakan dalam penelitian ini adalah triangulasi dengan sumber dan

\footnotetext{
${ }^{1}$ Christoph Barth and Marie Claire Barth, Teologi Perjanjian Lama 2 (Jakarta: BPK Gunung Mulia, 2008). $5-6$

${ }^{2}$ Soejono dan Abdurrahman, Metode Penelitian Suatu Pemikiran dan Penerapannya (Jakarta: RenekaCipta,1999), hal, 25.

${ }^{3}$ Lexy J. Moleong, Metodologi Penelitian Kualitatif (Bandung: PT Remaja Rosdakarya Offset, 2007), hal 330.
} 
metode, yang berarti membandingkan dan mengecek derajat balik kepercayaan suatu informasi yang diperoleh melalui metode kualitatif. ${ }^{4}$

\section{HASIL DAN PEMBAHASAN}

\section{Tanah Dalam Riwayat Israel}

\section{Tanah adalah Tema Penting dalam Perjanjian Lama}

Cerita penebusan terhadap Israel di dalam Alkitab dimulai dengan janji-janji Allah kepada Abraham. Unsur yang pokok dari janji itu, sebagaimana dinyatakan dan diulang dalam cerita-cerita tentang para bapak leluhur adalah bahwa Allah akan memberikan tanah kepada Abraham dan keturunannya (bnd. Kej. 12:1-3). Tanah tersebut menjadi salah satu ciri yang paling menonjol dari rangkaian cerita Perjanjian Lama. Itulah sebabnya jka memperhatikan cerita dari kitab-kitab Perjanjian Lama, jelaslah tema utama dari sejarah besar kelima kitab Taurat, Kitab Yosua dan kitab-kitab para nabi sampai pembangunan Kerajaan Daud adalah janji dan pemilikan tanah. ${ }^{5}$

Kelima kitab Taurat misalnya, membangkitkan ketegangan yang luar biasa mengenai tanah itu. Dimulai dari kitab Kejadian yang menceritakan janji kepada Abraham dan bagaimana para bapak leluhur Israel mengembara di tanah tersebut, bagian ini diakhiri dengan kitab Ulangan yang merinci kembali riwayat Israel ke belakang dan bagaimana mereka diperintkan terus menerus supaya tetap setia berpegang pada perjanjian Allah (Ul. $1-11)$.

Kitab Yosua bertemakan hal yang menyangkut tanah perjanjian itu, yakni penyerbuan, penaklukan dan pembagiannya. Namun di dalam kitab Hakim-Hakim ditunjukkan bahwa penaklukan yang mula-mula ternyata belum sempurna. Tanah perjanjian masih menjadi tanah perjuangan. Hakim terakhir dan terbesar, Samuel, memperoleh kemenangan yang membuat mereka dapat bertahan selama masa pemerintahannya (1 Sam. 7). Tetapi ketegangan kembali terjadi dan berakhir dengan kemenangan-kemenangan Daud yang terus menerus dan masa pemerintahannya yang panjang, Israel akhirnya dapat hidup dengan tenteram dalam batas-batas yang aman dari wilayah yang dijanjikan itu (2 Sam. 8, 10). Akhirnya janji itu nyata dan efektif digenapi.

Sekalipun telah dimiliki, tema tanah tidak hilang dari cerita Perjanjian Lama selanjutnya. Penindasan dan ketidakadilan di Israel pada abad-abad setelah Salomo, membuahkan ledakan baru dari kegiatan kenabian. Unsur yang mengejutkan dalam pemberitaan para nabi adalah ancaman akan pengasingan dari tanah itu. Artinya, kepemilikan bangsa Israel atas tanah Kanaan harus tetap menjadi perhatian yang serius bagi bangsa Israel, sampai kapanpun.

Hal itu memperlihatkan bahwa tema tanah adalah salah satu tema yang dominan di dalam Perjanjian Lama. Tanah dalam semua dimensinya berupa janji, penaklukan,

\footnotetext{
${ }^{4}$ Lexy J. Moleong, Metodologi Penelitian Kualitatif, hal 330.

${ }^{5}$ Chrisptopher J H Wright, Hidup Sebagai Umat Allah : Etika Perjanjian Lama (Jakarta: BPK Gunung Mulia, 2003).46
} 
pemilikan dan pembagian, penggunaan dan penyalahgunaan, kehilangan dan perolehan kembali adalah suatu kesatuan yang dasarnya bersifat teologis. Tanah bagi Israel adalah bagian dari pola penebusan juga, karena bentuk sosial Israel erat terikat dengan persoalanpersoalan ekonomi mengenai pembagian, pemilikan dan penggunaan tanah itu. ${ }^{6}$

\section{Pemberian Tanah sebagai Bentuk Kesetiaan Allah}

Kesetiaan Allah merupakan motif yang sering diungkapkan dalam pemberian negeri Kanaan kepada Israel. Kitab Yosua yang umumnya dianggap mempunyai dua bagian utama: penaklukan negeri itu (pasal 1-12) dan pembagiannya (pasal 13-24), sebenarnya secara keseluruhan menceritakan masuknya Israel ke Kanaan, negeri yang dijanjikan Allah kepada mereka. Negeri itu dahulu dijanjikan kepada para leluhur, kemudian diharapkan, dan akhirnya diklaim sebagai milik. Kendatipun seluruh negeri yang dijanjikan itu belum diduduki pada zaman Yosua, Israel mulai mendiaminya. Proses pendudukan dan penaklukkan negeri itu merupakan inti dari kitab Yosua. Kitab Yosua merupakan kitab yang melaporkan kemenangan-kemenangan bangsa Israel dalam usaha menaklukkan dan memiliki tanah perjanjian tersebut. Buku ini secara terus menerus menekankan bahwa kemenangan dan pretasi Israel hanya terlaksana karena bimbingan dan kuasa yang diberikan oleh Allah. ${ }^{7}$ Bangsa yang merupakan bekas budak di Mesir itu akhirnya menggapai kemenangan dan memiliki negerinya sendiri. Catatan diberikannya negeri itu kepada Israel oleh Allah adalah penyataan utama tentang kesetiaan-Nya memenuhi janji dalam perjanjian-Nya. ${ }^{8}$ Jika Allah berjanji maka umat-Nya dapat mengharapkan penggenapannya, betapapun itu kelihatannya sangat berat.

Allah telah setia membawa Israel masuk negeri yang telah dijamin-Nya dalam Perjanjian Abraham. Kepemilikan itu adalah pemberian Allah. Tetapi pendudukan atas semua daerah yang dijanjikan serta kemenangan atas bangsa-bangsa penghuni asli bergantung pada kesetiaan Israel menaati Perjanjian Musa. ${ }^{9}$ Artinya, sekalipun kepemilikan tanah itu adalah pemberiaan Allah, ketaatan Israel sangat diperlukan agar pemberian Allah itu dimiliki secara penuh.

\section{Signifikansi Kepemilikan Tanah Kanaan}

Sebagaimana telah diuraikan, Israel memiliki tanah untuk didiami karena Allah sudah memberikannya kepada mereka. Tradisi pemberian tanah ini mempunyai implikasiimplikasi yang luas atas pemikiran dan praktik Perjanjian Lama. Wright misalnya menyatakan ada empat implikasi dari hal tersebut. ${ }^{10}$ Yang pertama, pemberian tanah itu

\footnotetext{
${ }^{6}$ Ibid. 50

${ }^{7}$ L Thomas Holdcroft, Kitab-Kitab Sejarah (Malang: Gandum Mas, 1992).1

${ }^{8}$ Roy B Zuck, Eugene H Merrill, and Darrel L Bock, A Biblical Theology of The Old Tsetament (Malang: Gandum Mas, 2001).111

${ }^{9}$ Ibid. 112

${ }^{10}$ Wright, Hidup Sebagai Umat Allah : Etika Perjanjian Lama.51-55
} 
adalah deklarasi bahwa Israel sama sekali bergantung kepada Allah. Israel tidak boleh menganggap mereka mempunyai klaim apa pun terhadap tindakan Allah demi mereka: mereka sudah dan selalu akan tergantung sepenuhnya pada kasih dan kesetiaan Allah (bnd. Ul. 7:7-8; 8:17-18; 9:5). Yang kedua, pemberian tanah adalah deklarasi bahwa Allah dapat diandalkan. Ia bukan hanya Allah yang telah memberikan tanah, tapi juga yang akan terus memberikan berkat pemeliharaan kepada Israel (Mzm. 136; bnd. Ul. 26:5-10).

Yang ketiga, pemberian tanah berfungsi sebagai bukti hubungan antara Allah dan Israel. Israel mengetahui mereka adalah umat Allah karena ia telah memberikan kepada mereka tanah-Nya. Pemberian itu membuktikan hubungan yang terkait kepada perjanjian dengan abraham dan perjanjian Sinai dengan seluruh bangsa itu. Dan keempat, tradisi pemberian tanah yang historis inilah yang menghasilkan hak pemilikan pribadi di Israel. Orang Israel tidak hanya mengerti tanah sebagai suatu pemberian kepada segenap bangsa itu, melainkan menerobos sampai ke lapisan sosial terendah, sehingga setiap rumah tangga dapat merasakan hak atas tanah yang dimilikinya, dijamin oleh Allah sendiri.

Di samping apa yang diuraikan oleh Wright, ada beberapa signifikansi lain yang bisa diuraikan di bagian ini.

\section{Penggenapan Perjanjian}

Kepemilikian tanah Kanaan bagi Israel tidak bisa dipisahkan dari penggenapan janji Allah kepada Israel yang pertama kali diungkapkan kepada Abraham. Tanah itu jelas dipahami sebagai tanah yang dijanjikan kepada para leluhur Israel (bnd. Ul.1:8, 35; 6:10, 18, 23; 7:13, dst.,) sehingga Israel menyebutnya sebagai "milik pusaka Yahweh" (1 Sam. 26:16; 2 Sm. 21:3; 1 Raj. 8:36). ${ }^{11}$ Artinya, tanah itu adalah tanah yang memang dijanjikan dan dipersiapkan oleh Allah untuk dimiliki oleh Israel sehingga kepemilikannya menjadi bukti penggenapan janji tersebut.

Uniknya, salah satu tema yang menonjol di dalam Perjanjian Lama adalah, sekalipun tanah itu sudah dijanjikan untuk dimiliki oleh Israel dari masa Abraham, kepemilikan mereka atas tanah tersebut, atau penggenapan perjanjian tersebut juga dikatakan bergantung pada ketaatan mereka terhadap Allah dan hukum-Nya. Jika mereka taat terhadap hukum Taurat, mereka akan diberkati dan tetap berdiam di tanah perjanjian tersebut, namun jika tidak maka sebaliknya yang akan terjadi, mereka akan mendapat penghukuman. ${ }^{12}$

Fakta tersebut tentunya tidak memungkiri kenyataan bahwa kepemilikan tanah Kanaan adalah penggenapan dari Perjanjian Allah, bahkan justru meneguhkannya. Kenyataan bahwa status Israel di tanah perjanjian ditentukan oleh ketaatan mereka terhadap hukum Taurat justru menegaskan bahwa tanah itu adalah hasil pemberian Allah sesuai perjanjian yang Ia ikat baik kepada Abraham maupun Israel sebagai bangsa.

\footnotetext{
${ }^{11}$ Walter C Kaiser Jr, Teologi Perjanjian Lama (Malang: Gandum Mas, 2000).166

12 David M Howard Jr, Kitab-Kitab Sejarah Dalam Perjanjian Lama (Malang: Gandum Mas, 2002).113
} 
Namun perlu juga dicatat bahwa sekalipun syarat ketaatan berlaku dalam kepemilikan tanah tersebut, tetap saja karena dasar dari kepemilikan itu adalah janji Allah kepada Abraham yang tak bersyarat, ${ }^{13}$ maka pada akhirnya kepemilikan Israel akan tanah Kanaan tidak tergantung pada keberhasilan mereka menaati kehendak Tuhan, tapi tindakan sepihak Allah yang menggenapi janji-Nya. Sifat dan integritas Allah akan janji-Nya dibuktikan dengan menetapnya Israel di tanah Kanaan, tanah Perjanjian.

\section{Tempat Perhentian bagi Tuhan dan bagi Bangsa Israel}

Satu tema yang diulang-ulangi berkaitan dengan pentingnya kepemilikan tanah Kanaan bagi bangsa Israel adalah bahwa negeri tersebut menjadi tempat perhentian bagi Tuhan sekaligus bagi Israel. Tuhan membuat tanah Kanaan sebagai tempat perhentian-Nya (bnd. Mzm. 95:11; Yes. 66:1), Israel pun dijanjikan akan mendapat perhentian di tanah tersebut.

Janji bahwa tanah Kanaan adalah tempat perhentian bagi Israel sudah diungkapkan Musa sejak Keluaran 33:14 dan diulangi di Ulangan 3:20. Sekalipun kedua ayat tersebut menjanjikan "ketentraman" dan "keselamatan", akar katanya adalah "berhenti" sehingga menjadi sumber dari sebagian besar kata-kata untuk konsep perhentian. ${ }^{14}$ Perhentian ini merupakan suatu karunia bagi Israel, bagian dari warisan yang mereka terima dari Allah. Warisan tersebut terbagi menjadi dua, yaitu mengacu kepada negeri dan "perhentian" dari pertikaian terhadap para seteru. ${ }^{15}$ Meskipun bangsa Israel sebagai bangsa pilihan dan Allah terlebih dahulu menjanjikan tanah Kanaan menjadi bagian milik mereka. Namun diperlukan perjuangan untuk memilikinya, bangsa ini dituntut belajar patuh dan percaya (Bilangan 1:3). ${ }^{16}$

Bahkan, perhentian itu juga mengacu kepada aspek masa depan. Berdasarkan penggunaan akar kata "berhenti," dalam bahasa Ibrani, setidaknya konsep perhentian mengacu kepada tempat yang diberikan Tuhan, keamanan dan ketentraman dari musuhmusuh atau penghentian kesedihan dan kerja keras pada masa yang akan datang. ${ }^{17}$ Dari sini bisa dilihat bahwa konsep perhentian memiliki maksud yang lengkap. Konsep perhentian bukan saja berbicara tentang tempat di mana bangsa Israel berlabuh dan menetap setelah sebelumnya mengembara. Perhentian itu juga bermakna bahwa Israel menerima segala kepenuhan janji Allah di Kanaan baik untuk jangka waktu yang dekat maupun untuk jangka waktu yang sangat jauh ke masa depan. Tanah Kanaan adalah tempat perhentian bagi Israel, baik dari aspek fisik dan geografis maupun dari aspek rohani, selama-lamanya bagi Israel. Dengan demikian dapat disimpulkan bahwa konsep tanah Kanaan sebagai

\footnotetext{
${ }^{13}$ Paul Enns, Buku Pegangan Teologi (Malang: Literatur SAAT, 2003).57-58

${ }^{14} \mathrm{Jr}$, Teologi Perjanjian Lama.170

15 Jr, Kitab-Kitab Sejarah Dalam Perjanjian Lama. 112

${ }^{16}$ Fredy Simanjuntak, Ronald Sianipar, and Agustinus Sihombing, "Menelusuri Sejarah Perjalanan Misi Nomaden Bangsa Israel," Real Didache 4, no. 2 (2019): 1-24.

${ }^{17} \mathrm{Jr}$, Teologi Perjanjian Lama.170
} 
tempat perhentian Israel baik di masa itu maupun di masa yang akan datang memang menjadi hal penting dalam teologi Perjanjian Lama.

Selaras dengan itu, tanah Kanaan juga dikatakan adalah tempat perhentian Tuhan. Di Perjanjian Lama, perhentian adalah di mana kehadiran Allah berhenti (Bil. 10:33) atau di mana Ia tinggal (1 Taw. 28:2; Mzm. 132:8, 14; Yes. 66:1). ${ }^{18}$ Dengan demikian, perhentian Allah yang dimaksud adalah mengacu kepada tempat di mana Allah berkenan untuk menyatakan diri-Nya dan ditemui oleh umat-Nya.

Memang jika dikaitkan dengan kepemilikan tanah Kanaan, maka Israel perlu memiliki tanah tersebut karena Allah telah memilih tanah tersebut menjadi tempat kediaman-Nya, dan di salah satu bagian dari negeri itu Ia akan menegakkan nama-Nya (bnd. Ul. 14:23-25). Hal itu tentunya mengacu kepada Tabernakel atau yang sejak jaman Daud disebut Bait Allah, karena keberadaan tempat ibadah tersebut selalu diungkapkan sebagai tempat berdiamnya Allah. ${ }^{19}$ Tentu saja berdiamnya Allah berbeda dengan konsepkonsep penyembahan berhala yang menganggap Allah berdiam di sebuah kuil di mana manusia bertugas untuk memenuhi semua kebutuhan-Nya. Allah berdiam di bait-Nya di tempat yang telah Ia pilih dan tetapkan karena Ia ingin menyingkapkan diri-Nya. Itu adalah bentuk persekutuan-Nya dengan umat-Nya dimana Dia justru ingin menggenapi janji-janjiNya kepada umat-Nya. ${ }^{20}$ Dengan demikian, perhentian atau pendiaman Allah di salah satu tempat di tanah Kanaan adalah dalam rangka memelihara hidup bangsa itu, di mana di situ Ia akan memberkati hidup bangsa Israel sampai kepada kepenuhannya. Dengan demikian kepemilikan tanah Kanaan menjadi penting dalam kehidupan bangsa Israel karena melalui hal itulah Allah memiliki persekutuan yang dinamis dengan umat-Nya. Ia memiliki perhentian di antara orang Israel.

\section{Identitas dan Iman Bangsa Israel Dijaga}

Salah satu tema yang selalu diulangi di dalam Perjanjian Lama adalah tentang eksklusivitas bangsa Israel. Mereka diperintahkan oleh Allah untuk tidak bersekutu dengan bangsa-bangsa di sekitar Kanaan, tidak kawin campur dengan mereka dan harus senantiasa menjaga kekudusan mereka sebagai bangsa pilihan Allah dengan hidup tidak sama dengan bangsa-bangsa di sekitar mereka (bnd. Kel. 34:11-16; Ul. 20:10-18). Tema ini senantiasa dinyatakan sejak dari masa Abraham bahkan sampai masa pascapembuangan.

Sifat eksklusif tersebut tentunya sangat berkaitan dengan identitas Israel sebagai bangsa pilihan Allah. Sebagai bangsa yang kudus (Kel. 19:6) dan keturuan ilahi (bnd. Ul. 14:1; Mal. 2:15), mereka diperintahkan untuk hidup secara berbeda dari bangsa-bangsa lain, yaitu dengan menaati hukum Taurat Tuhan. Hal ini tentunya sangat berkaitan dengan

\footnotetext{
${ }^{18}$ Ibid. 170

${ }^{19}$ J Alec Motyer, The Minor Prophets, An Exegetical and Exposition (Grand Rapids: Baker Book House, 2000). 965

${ }^{20}$ Pieter Verhoef, The Books of Haggai and Malachi (Grand Rapids: Wm. B. Eerdmans Publishing Company, 1987).34
} 
rencana Allah bagi mereka agar melalui mereka, bangsa-bangsa akan mendapat berkat (bnd. Kej. 12:2-3). Memang janji itu mengacu kepada keturunan Abraham secara fisik, yaitu Israel. Namun tidak sedikit yang memahaminya sebagai mengacu kepada "keturunan" yang bersifat tunggal, yaitu Kristus. Atau sebagaimana yang diungkapkan oleh Kaiser, "keturunan" Abraham membentuk sebuah keseluruhan kolektif; hal ini dilambangkan melalui pergantian wakil-wakil yang bertindak sebagai materai dan jaminan sampai Kristus dendiri datang dari bangsa itu. ${ }^{21}$ Itu berarti peran Israel sangat penting bagi keselamatan dunia. Itulah sebabnya mereka harus menjaga identitas dan kekudusan mereka, agar rencana Allah atas dunia melalui Mesias dapat tergenapi.

Berdasarkan hal itu, bangsa Israel perlu hidup secara terpusat dalam satu kesatuan identitas dan iman yang sama. Mereka tidak boleh terserak, apalagi tidak memiliki negeri. Sebagai bangsa pilihan yang mengemban tugas penting, iman dan identitas mereka tidak boleh luntur. Itulah sebabnya mereka harus bersatu dalam suatu masyarakat yang bersifat Theokrasi. Dan pemusatan kehidupan mereka bersama-sama di satu negeri yang secara geografis saling berdekatan menjadi suatu faktor yang tidak bisa diabaikan di dalam penggenapan janji Allah terhadap mereka dan nenek moyang mereka. Itulah sebabnya Allah memberikan tanah Kanaan kepada mereka dan mereka perlu memilikinya.

\section{KESIMPULAN}

Kepemilikan tanah Kanaan bagi Israel sangatlah penting. Ia menempati posisi yang cukup sering dibahas dan diulangi dalam Perjanjian Lama. Kepentingannya tidak hanya berkaitan dengan hal-hal yang bersifat fisik, tapi juga menjangkau jauh ke dalam hal-hal teologis yang bersifat rohani. Tidak hanya mengantisipasi apa yang akan terjadi terhadap Israel dalam waktu dekat setelah mereka memasuki tanah tersebut, tapi menerobos jauh sampai kepada masa depan, bahkan akhir zaman.

Dengan demikian, dari sudut pandang Teologi Perjanjian Lama, kepemilikan tanah Kanaan bagi bangsa Israel benar-benar signifikan. Ia adalah bagian yang integral dari berbagai rencana Allah atas dunia ini, yang berujung pada keselamatan seluruh bumi.

\section{KEPUSTAKAAN}

Barth, Christoph, and Marie Claire Barth. Teologi Perjanjian Lama 2. Jakarta: BPK Gunung Mulia, 2008.

Enns, Paul. Buku Pegangan Teologi. Malang: Literatur SAAT, 2003.

Holdcroft, L Thomas. Kitab-Kitab Sejarah. Malang: Gandum Mas, 1992.

Jr, David M Howard. Kitab-Kitab Sejarah Dalam Perjanjian Lama. Malang: Gandum Mas, 2002.

Jr, Walter C Kaiser. Teologi Perjanjian Lama. Malang: Gandum Mas, 2000. Jr, Water C Kaiser. "Panggilan Misioner Israel." In Misi Menurut Prespektif Alkitab.

${ }^{21}$ Water C Kaiser Jr, "Panggilan Misioner Israel," in Misi Menurut Prespektif Alkitab (Jakarta: Yayasan Komunikasi Bina Kasih, 2007). 41 
Jakarta: Yayasan Komunikasi Bina Kasih, 2007.

Motyer, J Alec. The Minor Prophets, An Exegetical and Exposition. Grand Rapids: Baker Book House, 2000.

Simanjuntak, Fredy, Ronald Sianipar, and Agustinus Sihombing. "Menelusuri Sejarah Perjalanan Misi Nomaden Bangsa Israel.” Real Didache 4, no. 2 (2019): 1-24.

Verhoef, Pieter. The Books of Haggai and Malachi. Grand Rapids: Wm. B. Eerdmans Publishing Company, 1987.

Wright, Chrisptopher J H. Hidup Sebagai Umat Allah : Etika Perjanjian Lama. Jakarta: BPK Gunung Mulia, 2003.

Zuck, Roy B, Eugene H Merrill, and Darrel L Bock. A Biblical Theology of The Old Tsetament. Malang: Gandum Mas, 2001. 